\title{
LA INCAPACIDAD \\ DE LA MUJER CASADA Y SU SUPERACIÓN EN EL CÓDIGO CIVIL ESPAÑOL
}

Salvador Morales Ferrer

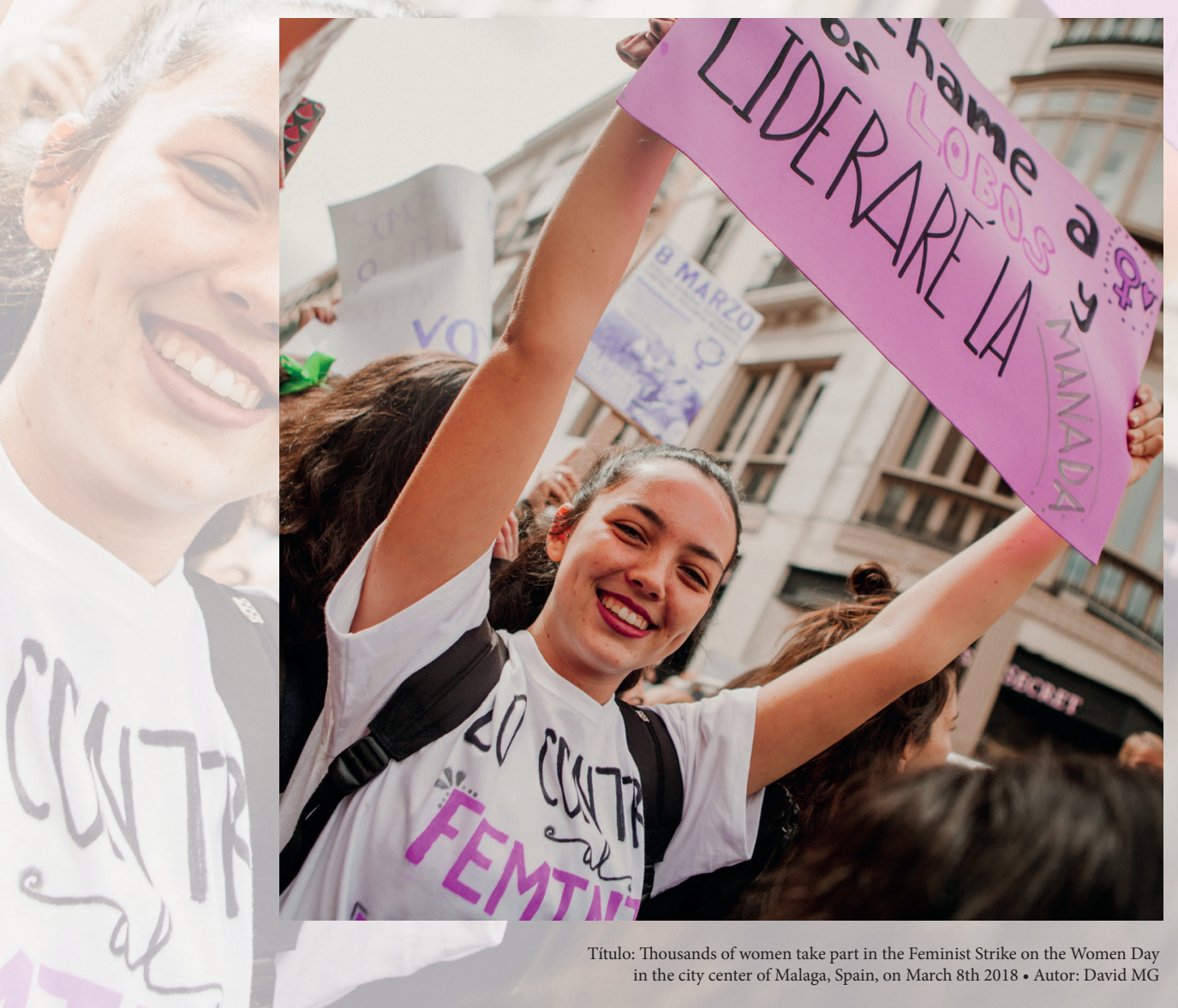





\title{
LA INCAPACIDAD DE LA MUJER CASADA Y SU SUPERACIÓN EN EL CÓDIGO CIVIL ESPAÑOL
}

\author{
Salvador Morales Ferrer \\ Ilustre Colegio de Abogados de Alzira
}

\section{Resumen}

La mujer ha sido marginada por el derecho civil español desde la redacción original del Código Civil de 1889, mediante sus diversas disposiciones discriminatorias, sustentadas en la protección de la mujer, equiparada con una persona incapacitada. El Código Civil español experimentó un largo y difícil recorrido, lleno de sucesivas reformas que contribuyeron a un ascenso satisfactorio de la mujer en el derecho civil. El presente artículo se enfoca en cuatro conceptos: la situación jurídica de la mujer en el siglo XIX, la igualdad de la mujer en la II República, el modelo franquista y la llegada de la democracia a España. Conjugados, todos los elementos son una herramienta para conocer en este siglo XXI la situación jurídica de la mujer en España. Este documento comprende cinco apartados: el primero esboza los inicios del concepto legal de la mujer cuando se promulgó el Código Civil de 1889; el segundo presenta el cambio del concepto legal de la mujer en la II República a causa de las bases del movimiento feminista; el tercero muestra el cambio de concepto de la mujer en la época del franquismo, con la desaparición de los derechos igualitarios y las causas de separación; el cuarto expone la promulgación de la Constitución española de 1978 y la llegada de la democracia, que devuelve el concepto igualitario entre el hombre y la mujer en el matrimonio; el quinto aborda las causas de separación en el contexto actual de España y la modificación del matrimonio.

Palabras clave: derecho, mujer, Código Civil, España.

El autor: doctor en Derecho. Miembro del Ilustre Colegio de Abogados de Alzira, Valencia (España). Correo electrónico: salvadormf@ono.com

Recibido: 7 de diciembre de 2017; evaluado: 21 de febrero de 2018; aceptado: 1 de marzo de 2018. 


\title{
OVERCOMING MARRIED WOMEN'S INCAPACITY UNDER THE SPANISH CIVIL CODE
}

\author{
Salvador Morales Ferrer \\ Ilustre Colegio de Abogados de Alzira
}

\begin{abstract}
The 1889 Spanish Civil Code reflected the marginalization of women through diverse discriminatory provisions that were founded on the idea of women's alleged weakness and need for protection, equating women with minors or incapacitated people. Thereafter, the Spanish Civil Code has undergone a long and difficult journey full of successive reforms that have contributed to a satisfactory ascent of women in Civil Law. This article focuses on four concepts: the legal situation of women in the nineteenth century, women's struggle for equality in the Second Republic, the Francoist model and the legal concept of women, and the arrival of democracy in Spain. Together, these four elements are a tool to understand the legal status of women in Spain. This article is divided into five sections: the first studies the definition of women when the Spanish Civil Code of 1889 was enacted, its legislative application to women and its legal concept; the second one examines how the legal concept of women changed in the Second Republic through the foundation of the feminist movement; the third analyzes changes in the concept of women in the Franco era with the disappearance of egalitarian rights and causes of separation; the fourth presents the promulgation of the Spanish Constitution in 1978 and the arrival of democracy that reestablished the equal concept of men and women in marriage, while the fifth section addresses the causes of separation in the current Spanish context and the evolution of marriage.
\end{abstract}

Keywords: law, woman, Civil Code, Spain.

Author: Doctor of Law. Member of the Illustrious Bar Association of Alzira, Valencia (Spain). Email: salvadormf@ono.com

Received: December 7, 2017; evaluated: Febrary 21, 2018; accepted: March 1, 2018 


\section{Introducción}

El objetivo de analizar la situación de la mujer en el Código Civil español es tratar de aclarar el entorno jurídico y legal del derecho privado que afecta a la mujer, mediante un estudio jurídico-político de varias épocas en torno a la figura de la mujer; ello, sin duda, facilitará un encaje en el Código Civil español y sus disposiciones.

Durante el siglo XIX, las mujeres conformaban la mayoría del Estado español, en buena proporción, solteras, casadas y viudas. Todas las mujeres eran educadas para el mantenimiento del hogar, el cuidado de los hijos y la atención a los esposos. Sostiene Torrero: "La familia puede ser definida, desde un punto de vista estrictamente jurídico como un conjunto de personas unidas por matrimonio". ${ }^{1}$

En el siglo XX, tras la promulgación de la II República, los movimientos feministas lograron la igualdad entre el hombre y la mujer en el matrimonio hasta la llegada de la dictadura, cuando el Legislador siguió los pasos del antiguo Código Civil español de 1889. En el siglo XXI, el Legislador atiende a la igualdad entre el hombre y la mujer tras la promulgación de la Constitución de 1978, cuyo Artículo 32.1 señala: "El hombre y la mujer tienen derecho a contraer matrimonio con plena igualdad jurídica". ${ }^{2}$

Con el presente artículo se pretende hacer un análisis descriptivo en los efectos jurídicos y personales que surgen entre los cónyuges en el momento de contraer matrimonio, con hincapié en la igualdad de derechos y deberes entre el hombre y la mujer.

En el primer apartado se desarrolla el concepto jurídico de la mujer en el siglo XIX; el segundo consiste en la influencia del movimiento feminista; el tercero aborda la desigualdad de la mujer en matrimonio; el cuarto revisa los conceptos jurídicos de igualdad de la mujer en el matrimonio y el quinto trata los efectos jurídicos de la mujer en el matrimonio.

Magda Torrero Muñoz, "Familia y matrimonio" en Curso básico de derecho de familia y sucesiones, coord. Juan Manuel Llopis Giner Valencia: Editorial práctica del derecho, 2003), 35.

2 España, "Constitución española de 1978", art. 32.1, https://www.laconstitucion.es/indice-de-la-constitucionespanola.html (acceso diciembre 3, 2017). 


\section{El concepto de la mujer en el Código Civil español durante el siglo XIX}

Existía un concepto patriarcal en España, como se menciona en el proyecto del Código Civil: "El marido debe proteger a la mujer, ésta obedecer al marido". ${ }^{3}$ Norma injusta que supone la inferioridad de la mujer, institucionalizada en la autoridad marital, como afirma la doctrina: "[... la primacía se otorgaba al marido". ${ }^{4}$

Por otro lado, Díez Picazo y Gullón expresan:

[... ] una de las cualidades naturales de la persona sobre la que los ordenamientos han establecido una profunda diferencia en el trato del varón, hasta el punto de que han existido épocas en que la mujer era considerada como persona incapaz (imbelitas sexus, imbecilitas mulierum), a quien sometía siempre a un poder tuitivo del marido, del padre, del tutor, etc. Si bien nuestro Código Civil heredó en alguna medida esta concepción, supuso una mejora en su condición al levantar ciertas incapacidades de obrar de la mujer casada en algunos puntos, en beneficio suyo y de la familia. ${ }^{5}$

Por su parte, Torralbo manifiesta:

[...] el Derecho está concebido por y para los hombres dedicándose a regular la situación de la mujer dentro del ámbito familiar y por el papel que en él desempeñaba, lo que daba lugar a un trato absolutamente discriminatorio supeditado al poder masculino. ${ }^{6}$

Del mismo modo entiende la doctrina la supeditación de la mujer al cónyuge masculino.

3 Francisco García Goyena, "Concordancias, motivos y comentarios del Código Civil español", art. 57, http:// fama2.us.es/fde/ocr/2007/concordanciasDelCodigoCivilT1.pdf (acceso diciembre 3, 2017).

4 José Luis La Cruz Bermejo y Manuel Albadalejo, Derecho de familia y su economía (Barcelona: Bosch, 1963), 164.

5 Luis Díez Picazo y Antonio Gullón, Sistema de derecho civil, vol. I, 2a ed. (Madrid: Tecnos, 1977), 295.

6 Ángela Torralbo Ruíz, El rol de la mujer en el Código Civil: Especial referencia a los efectos personales del matrimonio (Salamanca: Universidad de Salamanca, 2011), 6. 


\section{El Código Civil español y la mujer durante la II República}

El cambio radical en el siglo XX surgió con la promulgación de la Constitución de la II República Española:

La familia está bajo la salvaguardia especial del Estado. El matrimonio se funda en la igualdad de derechos para ambos sexos, podrá disolverse por mutuo disenso o a petición de cualquiera de los cónyuges, con alegación en este caso de justa causa. ${ }^{7}$

Fue muy avanzada para su tiempo tanto acerca de la igualdad entre el hombre y la mujer como de la disolución matrimonial, pero al final se quedó en un precepto casi pragmático, dado su escaso desarrollo legislativo, pues la Ley de matrimonio civil del 28 de junio de 1932 no modificó el Artículo $57^{8}$ del Código Civil de 1889.

Por el contrario, en la legislación catalana de la República denominada Llei sobre la capacitat jurídica de la dona i dels cónyuges, del 19 de junio de 1934, dictada por la Generalitat de Catalunya, se indicaba: "La mujer tiene la misma capacidad civil que el hombre. Esta igualdad no impide las disposiciones particulares de cada uno de los sexos". ${ }^{9}$ Se entiende que en esta época inició la igualdad entre el hombre y la mujer, por los ideales de la Revolución francesa que el Legislador español intentó introducir en la Constitución de la II República, así como hiciera el Legislador catalán.

En la Constitución de la II República se asentaron las primeras bases feministas, lo que contribuyó al acceso a la vida política y profesional, como lo hizo Victoria Kent con la Dirección General de Prisiones, quien propuso innovaciones y brindó un estatus personal de la mujer.

España, "Constitución de la República española”, art. 43, www.congreso.es/constitucion/ficheros/historicas/ cons_1931.pdf (acceso diciembre 2, 2017).

8 "El marido debe proteger a la mujer, ésta obedecer al marido". García Goyena, "Concordancias, motivos y comentarios del Código Civil español".

9 "La dona té la mateixa capacitat civil que l'home. Aquesta igualtat no impedeix les disposicions particulars a un dels dos sexes". Parlament de Catalunya, Llei sobre la capacitat jurídica de la dona i dels cónyuges (Barcelona: Butlletí Oficial de la Generalitat de Catalunya No. 2, 19 de junio de 1934), art. 1. 


\subsection{El Código Civil español: su repercusión en la mujer durante la época franquista}

En esta época desaparecieron todos los logros del período republicano respecto a la mujer, pues se promulgó una legislación que abolió todos sus derechos igualitarios: "El franquismo acabó con todos los avances que en el ámbito del derecho privado se habían alcanzado durante el periodo republicano". ${ }^{10}$

En el ámbito privado o doméstico siguió rigiendo el Código Civil de 1889. Por tanto, sin licencia de su marido, la mujer no podía adquirir a título oneroso ni lucrativo, enajenar sus bienes ni obligarse, excepto en los casos que disponía la ley. Se designó al marido como administrador único de los bienes gananciales del matrimonio, salvo estipulación en contrario. Los bienes parafernales, los bienes propios de la mujer y los bienes dotales podían ser administrados por ella, pero no podía gravarlos, enajenarlos o hipotecarlos sin la previa licencia del esposo, quien era la cabeza de familia.

Las Leyes Fundamentales del Reino, dictadas por el general Franco, instituían: "El matrimonio será uno e indisoluble", 11 el Código Civil español sostenía: "El marido es el administrador de los bienes de la sociedad conyugal". ${ }^{12}$ Así lo explica Díez Picazo:

[...] la Ley de 1958 como ahora se dice vulgarmente, dentro de unos cauces. Recordando la exposición de motivos: "Se contempla, por tanto, la posición peculiar de la mujer casada en la sociedad conyugal, en la que por exigencias de la unidad matrimonial existe una potestad de dirección que la naturaleza, la religión y la historia atribuyen al marido dentro de un régimen en el que se recoge fielmente el sentido de la tradición católica, que ha inspirado siempre, y debe inspirar en lo sucesivo, las relaciones entre los cónyuges". ${ }^{13}$

En la época franquista se consideraba que la mujer era inferior respecto al hombre debido a su naturaleza orgánica y su dependencia era tanto económica como teológica:

10 María Ángeles Moraga García, "Notas sobre la situación jurídica de la mujer en el franquismo", Feminismo/s, núm. 12 (2008): 235.

11 España, Presidencia del Gobierno, Decreto 779 de 1967, "Por el que se aprueban los textos refundidos de las Leyes Fundamentales del Reino" (Madrid: Boletin Oficial del Estado No. 9, 11 de enero de 1967), art. 22.2.

12 España, Jefatura de Gobierno, Ley 14 de 1975, "Sobre reforma de determinados artículos del Código Civil y del Código de Comercio sobre la situación jurídica de la mujer casada y los derechos y deberes de los cónyuges" (Madrid: Boletín Oficial del Estado No. 107, 5 de mayo de 1975), art. 59.

13 Luis Díez Picazo, Familia y derecho (Madrid: Civitas, 1984), 46-47. 
Así como la incapacidad general no ha pasado al Derecho moderno, en cambio la llamada incapacidad de la mujer casada, subsistía todavía en nuestro Derecho hasta la ley de 2 de mayo de 1975, pues el Código civil se inspiró en el sistema subordinado de la mujer al marido y las leyes de 24 de abril de 1958 y 22 de julio de 1961 han mantenido la autorización marital, seguida, en aras del principio de unidad de dirección. ${ }^{14}$

Por otro lado, Ragel señala:

[... las modificaciones posteriores del Código civil y de la Ley de Enjuiciamiento civil, se podía considerar que las solteras y viudas eran casi iguales que el hombre en derechos, pero la asignatura pendiente seguía siendo la situación de la mujer casada. ${ }^{15}$

Tras la promulgación de la Ley del 2 de mayo de 1975, que reguló la capacidad de la mujer casada, se abandonó el anticuado principio de autoridad marital y se inspiró en el principio de no modificación de la capacidad de los cónyuges por razón de matrimonio; ello es para la mujer una situación de equiparación en numerosos puntos en los que antes estaba sujeta a la autoridad marital. Cabe mencionar la Ley 14 de 1975, sobre reforma de determinados artículos del Código Civil y del Código de Comercio sobre la situación jurídica de la mujer casada y los derechos y deberes de los cónyuges: "El matrimonio no restringe la capacidad de obrar de los cónyuges". ${ }^{16}$

Sin embargo, la Ley no abordó el tema de la autoridad de los padres sobre los hijos, que se regía por el principio de la jefatura paterna y la madre quedaba relegada al supuesto de imposibilidad de ejercicio de patria potestad.

Hasta el año 1975 el marido y padre dirigía por plenos poderes la vida de la familia podía exigir obediencia a la mujer, la desaparición en 1975, del deber de obediencia de la mujer, introduce una nueva variable en la jefatura de la familia y las decisiones en la vida del grupo. Conserva el marido, aparte la patria potestad con el consiguiente usufructo de los bienes de los hijos, la

14 Diego Espín Cánovas, Manual de derecho civil español. 6a ed. (Madrid: Revista de Derecho Privado, 1977), 266.

15 Luis Felipe Ragel Sánchez, "Evolución histórica de los derechos de la mujer", Anuario de la Facultad de Derecho, núms. 12-13 (1994-1995): 331.

16 España, Jefatura de Gobierno, Ley 14 de 1975, art. 62.1. 
dirección de la comunidad de gananciales, y por tanto parece ser él, a través de su imperio sobre el patrimonio familiar. Sin embargo, a través del nuevo principio de independencia personal de la mujer, ya entonces la vida familiar se sometía en cierta medida a una dirección colegiada. ${ }^{17}$

Aunque en cierta medida el Legislador franquista ofreció cierta libertad a la mujer respecto al marido en sus bienes privativos y dotales al cambiar el término "autorización" por el de "consentimiento" y podía adquirir bienes y derechos a título oneroso y lucrativo para enajenar y obligarse, los bienes adquiridos en el matrimonio seguían siendo administrados por el marido.

Por otro lado, en el derecho penal se reflejó la superioridad del hombre sobre la mujer en el matrimonio, como en el Artículo 449: "El adulterio será castigado con la pena de prisión menor. Cometen adulterio la mujer casada que yace con varón que no es su marido, el que yace con ella, sabiendo que es casada, aunque después se declare nulo el matrimonio"18 y en el Artículo 450: "No se impondrá pena por delito de adulterio sino en virtud de querella del marido agraviado". Se entiende que en el matrimonio aún existía una prevalencia del hombre sobre la mujer, materializado en el derecho español.

\section{El Código Civil español y sus modificaciones y causas de separación durante la época franquista y la transición}

El derecho civil español se modificó y definió las causas de separación matrimonial como mencionaba el Código Civil de 1975:

Son causas de separación: $1^{\text {a }}$ El abandono injustificado del hogar, la infidelidad conyugal, la conducta injuriosa o vejatoria y cualquier otra violación grave o reiterada de los deberes conyugales. No podrá invocarse como causa la infidelidad conyugal si existe previa separación de hecho libremente consentida por ambos o impuesta por el que la alegue. $2^{a}$ Cualquier violación grave o reiterada de los deberes respecto a los hijos comunes o respecto de los que cualquiera de los cónyuges convivan en el hogar familiar. $3^{\text {a }}$ La condena a pena de privación de libertad por tiempo superior a seis años. $4^{\mathrm{a}} \mathrm{El}$ alcoholismo,

${ }^{17}$ José Luis La Cruz Bermejo y Francisco de Asís Sancho Rebullida, Derecho de familia. Elementos de derecho civil, IV (Barcelona: Bosch, 1982), 97.

18 España, Leyes penales. 2a ed. (Madrid: Civitas, 1976), 133. 
la toxicomanía o las perturbaciones mentales, siempre que el interés del otro cónyuge o el de la familia exijan la suspensión de la convivencia. $5^{\text {a }}$ El cese efectivo de la convivencia conyugal durante seis meses, libremente consentido. Se entenderá libremente prestado este consentimiento cuando el cónyuge requiriese fehacientemente al otro para prestarlo, apercibiéndole expresamente de las consecuencias de ello, y éste no mostrase su voluntad en contra por cualquier medio admitido en derecho o pidiese la separación o las medidas provisionales. $6^{a}$ El cese efectivo de la convivencia conyugal durante el plazo de tres años. $7^{a}$ Cualquiera de las causas de divorcio en los términos previstos en los números $3^{\circ}, 4^{\circ}$, y $5^{\circ}$ del artículo $86 .{ }^{19}$

\section{La reforma del Código Civil español tras la proclamación de la Constitución de 1978}

La Constitución de 1978 señala: "Los españoles son iguales ante la ley, sin que pueda prevalecer discriminación alguna por razón de nacimiento, raza, sexo, religión, opinión o cualquier otra condición o circunstancia personal o social”. ${ }^{20}$

Por su parte, el Tribunal Constitucional sostiene:

El desconocimiento del principio de igualdad del art. 14, se habría producido porque "la administración pese a conocer la existencia de un matrimonio islámico consideró que el interesado y la fallecida eran pareja de hecho, porque el matrimonio no había sido inscrito en el Registro Civil". ${ }^{21}$

Más expresivo es el Artículo 32.1 de la Constitución: "El hombre y la mujer tienen derecho a contraer matrimonio con plena igualdad jurídica",22 establece dicha igualdad no solo circunscrita a la realización del negocio jurídico matrimonial, sino que abarca también a la propia relación jurídico-matrimonial y la consigna en el Código Civil de 1981: "El marido y la mujer son iguales en derechos y deberes". ${ }^{23}$

19 España, Ley 30 de 1981, "Por la que se modifica la regulación del matrimonio en el Código Civil y se determina el procedimiento a seguir en las causas de nulidad, separación y divorcio" (Madrid: Boletín Oficial del Estado No. 172, 20 de julio de 1981), art. 8224.

20 España, "Constitución española de 1978", art. 14

21 España, Tribunal Constitucional, Sala Segunda, Sentencia 194 de 1 de diciembre de 2014, M. P. doña Adela Asua Batarrita.

22 España, "Constitución española de 1978", art. 32.1.

23 España, Ley 30 de 1981, art. 66. 
Al respecto, Díez Picazo menciona: "En 13 de mayo de 1981, la reforma del régimen económico-conyugal [...] ha sido una consecuencia inmediata del principio de igualdad jurídica de los cónyuges". ${ }^{24}$

De otro lado, Sánchez manifiesta:

La idea de igualdad de mujeres y hombres, en cuanto inspiradora de nuestra civilización, es de muy tardía aparición. Frente a la secular creencia generalizada - compartida por los máximos pensadores del pasado y por el común de los pueblos- de que la mujer era por naturaleza inferior al hombre $[\ldots] .^{25}$

El Legislador aplicó la igualdad entre el hombre y la mujer muy tardíamente, a causa de la influencia de cuestiones históricas, políticas, culturales y democráticas.

\section{El Código Civil español en el siglo XXI y sus efectos sobre el matrimonio}

El Legislador anuló algunas causas de separación del Código Civil de 1975:

Se decretará judicialmente el divorcio, cualquiera que sea la forma de celebración del matrimonio, a petición de uno solo de los cónyuges, de ambos o de uno con el consentimiento del otro cuando concurran los requisitos siguientes y circunstancias exigidos en el artículo $81 .{ }^{26}$

El Artículo 81.2 señala:

Se decretará judicialmente la separación, cualquiera que sea la forma de celebración del matrimonio: A petición de uno solo de los cónyuges, una vez transcurridos tres meses desde la celebración del matrimonio. No será preciso el transcurso de este plazo para la interposición de la demanda cuando acredite la existencia de riesgo para la vida, la integridad física, la libertad, la integridad

24 Díez Picazo, Familia y derecho, 66.

25 Yolanda Sánchez-Urán Azaña, "La igualdad como valor, como principio y como derecho fundamental" en Igualdad de mujeres y hombres (Comentario a la Ley Orgánica 2/2007, de 22 de marzo, para la igualdad efectiva de mujeres y hombres), dir. Alfredo Montoya Melgar y coord. Yolanda Sánchez-Urán Azaña (Madrid: Civitas, 2007), 12.

26 España, Código Civil (Madrid: La Ley, 2006), art. 86. 
moral o libertad e indemnidad sexual del cónyuge demandante o de los hijos de ambos o de cualquiera de los miembros del matrimonio.

Por otro lado, existen ciertas posturas contrarias en la doctrina, entre las que cabe mencionar a Torrero:

El matrimonio, concebido como instituto natural, ya sea civil, tiene unos fines y unos caracteres que le son propios. Sus características son dos: la unidad e indisolubilidad. La unidad significa que el matrimonio es la unión entre un solo hombre y una sola mujer, consecuencia de la concepción monogámica que sobre el matrimonio existe en nuestro Derecho y en nuestra sociedad; la indisolubilidad, que la relación que surge entre los esposos es perpetua y permanente. En consecuencia puede ser disuelta por la muerte de uno de los cónyuges. Evidentemente, el legislador civil se ha apartado de esta segunda característica al admitir la disolución del matrimonio por el divorcio, a tenor del de lo dispuesto en el artículo 85 del Código civil: El matrimonio se disuelve, sea cual fuere la forma y el tiempo de su celebración, por muerte o la declaración de fallecimiento de uno de los cónyuges y por divorcio. Por ello, el matrimonio civil no puede considerarse como una unión perpetua, aunque sí estable. ${ }^{27}$

En la misma línea, pero con diferente matiz, expresa Sánchez Vidanes:

[... s según se entienda como una relación contractual o como un negocio jurídico bilateral complejo típico del Derecho de Familia. Sin entrar a disertar sobre dicho carácter, parece evidente que no se trata simplemente de un contrato, que también lo es, por cuanto los contrayentes actúan necesariamente sobre una base convencional, cual es el acuerdo de compartir la vida con el otro cónyuge. ${ }^{28}$

Por otro lado, el papel de la mujer en el matrimonio continúa con lo preceptuado en el Código Civil de 1975, aunque se exceptúa la creación de nuevos tipos de matrimonio: "El matrimonio tendrá los mismos requisitos y efectos cuando ambos contrayentes sean del mismo sexo". ${ }^{29}$ El Legislador español está en concordancia con lo que exigen los tiempos:

\footnotetext{
Torrero Muñoz, "Familia y matrimonio", 40-41.

28 Carmen Sánchez Vidanes, "Matrimonio" en Memento práctico. Familia y sucesiones, coord. José Ángel Martínez Sanchiz (Madrid: Francis Lefebvre, 2010), 12-13.

29 España, Código Civil, art. 44.2.
} 
El precepto presupone así un sujeto activo hombre y un sujeto activo mujer, exige además una relación conyugal o de afectividad análoga. Este elemento relacional no añade nada significativo a la discriminación por el sexo porque tal relación es concebible también en sujetos homosexuales. ${ }^{30}$

Al mismo tiempo, Ferrajoli manifiesta:

Pues bien, son fundamentales los derechos que no se pueden comprar ni vender, esto es, aquellos derechos subjetivos que corresponden a todos los seres humanos en cuanto dotados del estatus de personas, de ciudadanos o sujetos con capacidad de obrar. ${ }^{31}$

Los derechos adquiridos por las personas desde su nacimiento son fundamentales en todo el ordenamiento jurídico español.

Por otro lado, históricamente ha existido la supremacía del hombre sobre la mujer y en la actualidad ha degenerado en la violencia de género contra la mujer que se ha relacionado con la violencia física grave; sin embargo, la violencia comprende también malos tratos psicológicos, sexuales, de aislamiento y control social, que suelen pasar desapercibidos. Al respecto afirma el Tribunal Supremo Español: "[...] alterar gravemente el desarrollo de la vida cotidiana pero pueden aportar algunas pautas orientadoras que iluminen a la hora de enjuiciar otros supuestos que nunca serán iguales pero que pueden presentar semejanzas". ${ }^{32}$ Se entiende de la sentencia que existen otros elementos que concuerdan con la violencia de género y que serían aceptables. De acuerdo con Alexy: "[...] se propone alcanzar la mayor racionalidad posible en argumentaciones prácticas que tengan como propósito determinar lo que el derecho permite, prohíbe o manda". ${ }^{33}$

\footnotetext{
30 España, Tribunal Constitucional, Sala Plena, Sentencia 59 de 14 de mayo de 2008, M. P. Pascual Sala Sánchez. Luigi Ferrajoli, Los fundamentos de los derechos fundamentales (Madrid: Trotta, 2007), 21.

32 España, Tribunal Supremo, Sala Segunda, Sentencia 324 de 8 de mayo de 2017, M. P. Antonio Del Moral García.

33 Robert Alexy, Reicht, Vernunft, Diskurs (Fráncfort: Suhrkamp, 1995), 94.
} 


\section{Conclusiones}

En sus inicios, el Código Civil de 1889 infravaloró a la mujer por situaciones ancestrales históricas, sociales y teleológicas y la sometió al hombre en el matrimonio, al considerarla de inferior naturaleza.

La II República española promovió la igualdad de sexos en su Constitución de 1931, pues era el espíritu de la Revolución francesa.

En la época de la dictadura franquista se postergó la legislación avanzada de la II República española, con lo que se relegó a la mujer casada en ciertos ámbitos familiares e incluso penales.

Una vez proclamada la Constitución de 1978 se retomó la igualdad entre el hombre y la mujer en el ámbito familiar y la patria potestad de los hijos en el Código Civil español.

En 2005 se promovió el matrimonio entre las personas del mismo sexo.

\section{Referencias}

Alexy, Robert. Reicht, Vernunft, Diskurs. Fráncfort: Suhrkamp, 1995.

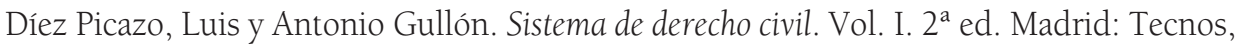
1977.

Díez Picazo, Luis. Familia y derecho. Madrid: Civitas, 1984.

España, Jefatura de Gobierno. Ley 14 de 1975, "Sobre reforma de determinados artículos del Código Civil y del Código de Comercio sobre la situación jurídica de la mujer casada y los derechos y deberes de los cónyuges". Madrid: Boletín Oficial del Estado No. 107, 5 de mayo de 1975.

España, Presidencia del Gobierno. Decreto 779 de 1967, "Por el que se aprueban los textos refundidos de las Leyes Fundamentales del Reino". Madrid: Boletín Oficial del Estado No. 9, 11 de enero de 1967.

España, Tribunal Constitucional, Sala Plena. Sentencia 59 de 14 de mayo de 2008. M. P. Pascual Sala Sánchez.

España, Tribunal Constitucional, Sala Segunda. Sentencia 194 de 1 de diciembre de 2014. M. P. doña Adela Asua Batarrita.

España, Tribunal Supremo, Sala Segunda. Sentencia 324 de 8 de mayo de 2017. M. P. Antonio Del Moral García. 
España. Código Civil. Madrid: La Ley, 2006.

España. "Constitución de la República española". www.congreso.es/constitucion/ficheros/ historicas/cons_1931.pdf (acceso diciembre 2, 2017).

España. "Constitución española de 1978". https://www.laconstitucion.es/indice-de-laconstitucion-espanola.html (acceso diciembre 3, 2017).

España. Ley 30 de 1981, "Por la que se modifica la regulación del matrimonio en el Código Civil y se determina el procedimiento a seguir en las causas de nulidad, separación y divorcio". Madrid: Boletín Oficial del Estado No. 172, 20 de julio de 1981.

España. Leyes penales. 2a ed. Madrid: Civitas, 1976.

Espín Cánovas, Diego. Manual de derecho civil español. 6ª ed. Madrid: Revista de Derecho Privado, 1977.

Ferrajoli, Luigi. Los fundamentos de los derechos fundamentales. Madrid: Trotta, 2007.

García Goyena, Francisco. "Concordancias, motivos y comentarios del Código Civil

Español”. http://fama2.us.es/fde/ocr/2007/concordanciasDelCodigoCivilT1.pdf (acceso diciembre 1, 2017).

La Cruz Bermejo, José Luis y Francisco de Asís Sancho Rebullida. Derecho de familia. Elementos de derecho civil, IV. Barcelona: Bosch, 1982.

La Cruz Bermejo, José Luis y Manuel Albadalejo. Derecho de familia y su economía. Barcelona: Bosch, 1963.

Moraga García, María Ángeles. "Notas sobre la situación jurídica de la mujer en el franquismo". Feminismo/s, núm. 12 (2008): 229-252.

Parlament de Catalunya. Llei sobre la capacitat jurídica de la dona i dels cónyuges. Barcelona: Butlletí Oficial de la Generalitat de Catalunya No. 2, 19 de junio de 1934.

Ragel Sánchez, Luis Felipe. "Evolución histórica de los derechos de la mujer". Anuario de la Facultad de Derecho, núms. 12-13 (1994-1995): 313-336.

Sánchez Vidanes, Carmen. "Matrimonio" en Memento práctico. Familia y sucesiones, coordinado por José Ángel Martínez Sanchiz, 12-13. Madrid: Francis Lefebvre, 2010.

Sánchez-Urán Azaña, Yolanda. "La igualdad como valor, como principio y como derecho fundamental" en Igualdad de mujeres y hombres (Comentario a la Ley Orgánica 2/2007, de 22 de marzo, para la igualdad efectiva de mujeres y hombres), dirigido por Alfredo Montoya Melgar y coordinado por Yolanda Sánchez-Urán Azaña, xx-xx. Madrid: Civitas, 2007.

Torralbo Ruíz, Ángela. El rol de la mujer en el Código Civil: especial referencia a los efectos personales del matrimonio. Salamanca: Universidad de Salamanca, 2011.

Torrero Muñoz, Magda. "Familia y matrimonio" en Curso básico de derecho de familia y sucesiones, coordinado por Juan Manuel Llopis Giner, 35-49. Valencia: Editorial práctica del derecho, 2003. 